Finn Reiestad MD, ${ }^{*}$ William B. Mcllvaine FRCPC, $\dagger$ Lars Kvalheim MD, $¥$ Per Haraldstad MD, * Bjorg Pettersen CRNA*

\title{
Successful treatment of chronic pancreatitis pain with interpleural analgesia
}

\begin{abstract}
Interpleural analgesia has recently been shown to be effective in the management of various chronic pain syndromes. We have used interpleural analgesia successfully in 11 patients with severe chronic pancreatitis of 24-38 months' duration. Daily injections of $30 \mathrm{ml}$ of 0.5 per cent bupivacaine with epinephrine $5 \mu \cdot \mathrm{ml}^{-1}$, were given through a percutaneously inserted pleural catheter over a five-to ten-day period. Patients have remained pain-free during follow up which ranges from 24 to 40 weeks. This method of providing analgesia for the patient suffering from the pain of chronic pancreatitis is simple, safe, effective and can be provided on an outpatient basis.
\end{abstract}

Key words

ANAESTHETIC TECHNIQUES: regional, interpleural catheter; ANAESTHETICS, LOCAL: bupivacaine; PAIN: pancreatitis

From the Department of Anesthesiology, *Ulleval University Hospital, Oslo 4 Norway, the †Department of Anesthesiology, The Children's Hospital, Denver CO 80218, and $¥$ Namdalen County Hospital, Namsos, Norway.

Address correspondence: Dr. Finn Reiestad, Department of Anesthesiology, Box B-113, University of Colorado Health Sciences Center, Denver CO, 80262.
Interpleural instillation of local anaesthetic solutions was originally described in 1984 by Kvalheim and Reiestad ${ }^{1}$ for postoperative pain relief. Since then, interpleural analgesia has been shown to be effective for postoperative pain management in patients undergoing cholecystectomy, breast surgery, and renal surgery with remarkably low blood levels of local anaesthetic achieved. ${ }^{2-4}$ Using the technique described by McIlvaine, good pain relief has been achieved in both children and adults undergoing thoracotomies..$^{5.6}$ Rocco and Reiestad have shown the efficacy of interpleural analgesia in patients with multiple rib fractures and flail chests. ${ }^{7}$ Reiestad and Kvalheim found the technique effective in treating severe acute and subacute thoracic herpes zoster, perhaps even preventing the development of chronic post-herpetic neuralgia. ${ }^{8}$ Recently the interpleural catheter technique has been shown to be effective in the treatment of various chronic pain conditions. ${ }^{9,10}$ We have used interpleural instillation of local anesthetics in several patients with chronic pancreatitis over the past two years. The method seems to offer safe, effective analgesia with haemodynamic stability and few side effects in contrast to other techniques such as coeliac plexus blockade.

\section{Methods}

After informed written consent had been obtained, 11 patients, ten male, with severe chronic pancreatitis were accepted for treatment with interpleural catheter analgesia. Pain was assessed on a verbal pain intensity score (PS) ranging from $P S=0$ (no pain) to PS $=10$ (intolerable pain). The aetiology of the pancreatitis in eight of the patients was alcohol abuse; one developed chronic pancreatitis after a cholecystectomy with gallstones in the common bile duct; and in three, the aetiology was unknown. All of the patients were using high doses of analgesics including opioids prior to the start of treatment. Before presentation to our Pain Clinic, four of the patients had undergone coeliac plexus block with local anesthetics on as many as three occasions with limited effect of short duration. Most of them also suffered from disruption of sleep, limited physical activity, and postprandial pain. All analgesics were withheld after the first interpleural 
instillation of local anaesthetic. The patients were assessed before and after each treatment.

All patients were monitored with ECG and automated blood pressure measurements were taken every two minutes for the first 20 minutes after injection and then at five-minute intervals. All patients had an intravenous catheter inserted before the interpleural catheter was placed. Patients were positioned in the horizontal lateral decubitus position with the painful side up. After sterile preparation of the skin, a small skin wheal was raised with a 25 SWG needle between the seventh and eighth ribs $8-10 \mathrm{~cm}$ from the posterior midline. A 16 SWG Tuohy epidural needle was introduced with the bevel cephalad. The needle was introduced towards the midline at an angle of $60-70^{\circ}$ and walked off the upper border of the eighth rib. After perforating the caudal intercostal membrane, the stylet was removed and a well moistened, freely moving 10 or $20 \mathrm{ml}$ glass syringe containing $3-5 \mathrm{ml}$ of air was attached to the needle. The syringe and the needle were then advanced as a unit. Entry into the pleural space was identified when the piston of the syringe was pulled down by the negative intrapleural pressure. An epidural catheter was then introduced $5-6 \mathrm{~cm}$ into the pleural cavity. The catheter was anchored at the skin with a clear adhesive dressing (Tegaderm ${ }^{2}$ ). Following negative aspiration of blood or air, $30 \mathrm{ml} 0.5$ per cent bupivacaine with epinephrine, $5 \mu \mathrm{g} \cdot \mathrm{ml}^{-1}$, were injected over six minutes and the patients were kept in the lateral decubitus position for an additional 20 minutes before being turned supine.

The patients received one $30 \mathrm{ml}$ injection of 0.5 per cent bupivacaine with epinephrine, $5 \mu \mathrm{g} \cdot \mathrm{ml}^{-1}$, every twenty-four hours until they were pain free or had reached a steady state. Steady state was defined as a stable pain intensity score in spite of repeated injections of local anaesthetic. The daily injections were continued for three days after the steady state was reached before the catheter was removed. Outpatients were informed about the symptoms of a pneumothorax and advised to return to the Emergency Room if they experienced difficulty in breathing, a rapid pulse or chest pain. A chest radiograph was obtained in all patients two hours after the interpleural catheter was inserted. The patients were seen and assessed daily during the cycle of injections. After the catheters were removed, they were seen weekly for several months. They were asked to contact the Pain Center in the event pain returned.

\section{Results}

Dramatic pain relief was reported by all patients after the first interpleural injection. The onset of relief started during the injection of local anaesthetic. Eight patients had left sided catheters inserted, three were right sided and none was bilateral. None of the patients required narcotics during the five to ten day cycle of injections and sleep patterns returned to normal without any medication. The patients were able to assume any position without pain and could move around freely. The duration of the pain and the results of the treatment are shown in the Table. Before treatment three of the patients were taking oral acetaminophen $500 \mathrm{mg}$ with codeine $30 \mathrm{mg}$ to a maximum of eight to ten tablets daily. The remaining patients were using two tablets daily of a long-acting oral preparation of morphine.

The patients had a decrease in PS from a mean of 8.9 to 0.54 after the first injection with a pain-free period of 10-20 hours. The number of daily injections necessary to achieve a pain-free state in eight patients or steady state pain in three patients varied from five to ten. Pain score at the end of the cycle of injections (mean $\pm S D$ ) was $0.3 \pm 0.6$. The duration of pain relief after this treatment has been remarkable. It varies from 24 to 40 weeks. Eight of 11 patients are still pain-free with the remaining three having only mild pain readily controlled with oral acetaminophen $500 \mathrm{mg}$. None requires daily medication.

Four of the eight patients whose pancreatitis was alcohol related were abusing alcohol in moderate doses before treatment to lessen the pancreatic pain in spite of heavy analgesic use. Of these four patients, three have not used alcohol since discharge from the treatment program. Five patients received oral oxazepam for one week in order to avoid problems of alcohol withdrawal.

One patient who was completely pain-free for 16 weeks after five injections began using alcohol again for approximately one week. The pancreatic pain returned with almost the same intensity as before the interpleural analgesic treatment. He returned to the Pain Control Center for another series of injections and achieved complete pain relief after six injections using the method described. Since that time he has been pain-free for another 18 weeks. The remaining patients have no need for opioids, have retumed to a normal life style with six returning to work.

Skin analgesia to pinprick was assessed bilaterally in all patients and none was found on either side. An ipsilateral Horner's Syndrome was seen in five patients after each interpleural injection. The syndrome developed 20 to 60 minutes after the local anaesthetic injection and persisted for four to six hours. There were no other complications.

\section{Discussion}

Chronic pancreatitis usually refers to a clinical entity rather than a specific pathological process. In the early stages, the patients suffer from very painful repeated attacks of acute pancreatitis which may be precipitated by alcoholism, biliary tract disease or other conditions. The typical patient with chronic pancreatitis is a $30-50$-year- 
TABLE Pain scores and demographic details

\begin{tabular}{|c|c|c|c|c|c|c|c|c|}
\hline Pt\# & Age & $\begin{array}{l}\text { Pain } \\
\text { Duration }\end{array}$ & $\begin{array}{l}P S \\
\text { Before }\end{array}$ & $\begin{array}{l}P S \\
\text { Immed }\end{array}$ & $\begin{array}{l}P S \\
\text { After }\end{array}$ & \# & $\begin{array}{l}P S \\
\text { Final }\end{array}$ & Followup \\
\hline 1 & 46 & 36 & 9 & 1 & 2 & 5 & 0 & 34 \\
\hline 2 & 31 & 38 & 10 & 0 & 2 & 10 & 0 & 36 \\
\hline 3 & 38 & 24 & 9 & 2 & 3 & 6 & 2 & 40 \\
\hline 4 & 36 & 30 & 9 & 1 & 2 & 5 & 0 & 29 \\
\hline 5 & 47 & 30 & 9 & 0 & 2 & 7 & 0 & 37 \\
\hline 6 & 42 & 28 & 10 & 1 & 3 & 8 & 1 & 28 \\
\hline 7 & 52 & 34 & 7 & 0 & 1 & 7 & 0 & 26 \\
\hline 8 & 48 & 24 & 9 & 1 & 3 & 5 & 0 & 30 \\
\hline 9 & 41 & 36 & 9 & 0 & 2 & 7 & 0 & 28 \\
\hline 10 & 44 & 36 & 8 & 0 & 2 & 6 & 1 & 32 \\
\hline 11 & 51 & 30 & 9 & 0 & 1 & 6 & 0 & 29 \\
\hline Mean & 43.3 & 31.4 & 8.9 & 0.54 & 2.1 & 6.5 & 0.3 & 30.8 \\
\hline S.D. & 6.5 & 4.9 & 0.8 & 0.7 & 0.7 & 1.5 & 0.6 & 4.9 \\
\hline
\end{tabular}

Age in years.

Duration of pain in months before treatment.

PS before treatment.

PS immediately after first injection.

PS when analgesia of first injection ends.

\# of injections given.

PS after cycle of injections completed.

Followup duration in weeks after completion of cycle.

old male with a long history of alcoholism and previous episodes of acute pancreatitis. After a variable period of time, the intermittent episodes of pain evolve to become persistent, continuous and intolerable. At this stage addiction to narcotics and to alcohol as an analgesic supplement is common. The pancreatic pain is often located in the epigastrium but may radiate to the back and/or towards one flank. The pain is typically relieved when the patient sits in a hunched position and is aggravated by lying supine. The approach to pain relief must also address the issue of addiction to alcohol and narcotics.

Pancreatic pain whether due to pancreatitis or carcinoma presents a great challenge to the pain specialist. The dominant method of treatment in this condition has been blockade of the coeliac ganglion with either local anaesthetics or neurolytic agents. The coeliac ganglion is located at the level of the first lumbar vertebra and represents the termination of the fibres of the greater splanchnic nerves in a bilateral diffuse mass of nerve tissue approximately $2 \mathrm{~cm}$ in diameter. Bilateral blockade is required for adequate relief of pain and necessitates a large volume of local anaesthetic or neurolytic agent. Possible complications include hypotension, subarachnoid blockade, epidural or intravascular injection, and retroperitoneal haemonthage from inadvertent aortic puncture. Because of the technical difficulty of this block correct placement of the needle tip may not be achieved.
Even a successful alcohol coeliac block may not lead to good prolonged pain relief in a patient with chronic pancreatitis. ${ }^{11}$

Although there are anatomical variations, the thoracic portion of the sympathetic chain contains a series of ganglia which correspond roughly to the thoracic spinal nerves. The trunk is covered by the costal portion of the parietal pleura. The splanchnic nerves arise from the caudal six or seven thoracic and first lumbar ganglia. Pancreatic pain is believed to be transmitted along afferent fibres from the pancreas to the splanchnic nerves and also by the lower intercostal nerves which innervate the peritoneum. ${ }^{10}$ The lower intercostal nerves also supply the upper part of the abdominal wall. It is therefore important to block both the lower intercostal and splanchnic nerves in order to relieve pain originating in the pancreas. Our results seem to indicate that this is achieved easily with interpleural analgesia. Diffusion of local anaesthetic from the pleural space seems to block several intercostal nerves simultaneously. The local anaesthetic is also believed to diffuse easily through the parietal pleural and this effectively blocks most of the intrathoracic sympathetic chain including the splanchnic nerves. Ipsilateral Horner's syndrome was obtained in five of our patients. The blockade of both somatic and visceral pain fibres in interpleural block is an important distinction when compared with coeliac plexus block.

Sihota et al. have shown that 14 patients who were given 
one single injection of local anaesthetic had a remarkable decrease in pancreatic pain with a duration of up to 12 days. When the pancreatic pain returned it was less severe in all patients. ${ }^{9}$ Our patients were given the same amount of local anaesthetic every 24 hours until the pain was eliminated or reduced to a tolerable level. This continuous technique resulted in complete pain relief in most cases. All patients were maintained at the same level of reduced pain 24 to 40 weeks after the conclusion of the interpleural injections. In our opinion the single shot technique can be used in outpatients with less severe chronic pancreatic pain, in patients with attacks of acute pancreatitis without severe continuous pain and in patients for whom daily injections of local anaesthetic are impossible. This technique can also be used if pain retums - possibly resulting in a longer duration of pain relief than after the first injection. The repeated injection technique is the method of choice in patients with severe chronic pain of pancreatic origin. This technique can also be offered to chronic pancreatitis patients in whom the attacks of acute pancreatitis are long lasting and or if they suffer from pain between the attacks. Both methods can be applied successfully in outpatients.

We provided continuous injections for three additional days after optimal pain reduction was achieved in order to obtain a more profound and prolonged block. Only further studies will demonstrate if this practice is correct. We believe that leaving the patient in the horizontal position with the most painful side up for $20 \mathrm{~min}$ after injection will facilitate the diffusion of the local anaesthetic through the costal portion of the parietal pleura resulting in a satisfactory block of the sympathetic trunk, the splanchnic nerves and the intercostal nerves as well. Our decision to use a volume of $30 \mathrm{ml}$ was based on our clinical experience. We were not attempting to characterize a minimum effective volume.

In our study the catheter was placed in the pleural space ipsilateral to the distribution of the pancreatic pain. We recommend reinsertion of the catheter in the contralateral pleural space if this procedure gives unsatisfactory pain relief as a result of bilateral innervation of the pancreas. This might also be the method of choice if the pancreatic pain is referred to the epigastrium. The prolonged pain relief after injection of interpleural local anaesthetic may be explained by reduction of the inflammatory reaction and relief of splanchnic vasoconstriction by interruption of the spinal reflex arc. ${ }^{10}$

In summary, we recommend interpleural catheter analgesia for treatment of the pain associated with chronic pancreatitis. The technique gives excellent long lasting pain relief, is safe, highly effective and easily performed with minimal discomfort to the patient.

\section{References}

1 Vvalheim L, Reiestad $F$. Intrapleural catheter in the management of postoperative pain. Anesthesiology 1984; 61: A231.

2 Reiestad F, Stromskag $K E$. Interpleural catheter in the management of postoperative pain - a preliminary repor. Regional Anesthesia 1986; 11: 88-91.

3 Brismar B, Petterson N, Tokics L, Strandberg A, Hedenstierna $G$. Postoperative analgesia with intrapleural administration of bupivacaine-adrenaline. Acta Anaesthesiol Scand 1987; 31: 515-20.

4 Stromskag KE, Reiestad F, Holmqvist E, Ogenstad $S$. Intrapleural administration of $0.25 \%, 0.37 \%, 0.5 \%$ bupivacaine with epinephrine after cholecystectomy. Anesth Analg 1988; 67: 430-4.

5 Mcllvaine WB, Knox RF, Fennessey PV, Goldstein $M$. Continuous infusion of bupivacaine via intrapleural catheter for analgesia after thoracotomy in children. Anesthesiology 1988; 69: 261-4.

6 Kambam JR, Handte RE, Flanagan J, Fischer K, Lupinetti $M$, Hammon J. Intrapleural anesthesia for post thoracotomy pain relief. Anesth Analg 1987; 67: $\mathbf{\$ 9 0 .}$

7 Rocco A, Reiestad F, Gudman J, McKay W. Intrapleural administration of local anesthetics for pain relief in patients with multiple rib fractures. Regional Anesthesia 1987; 12: $10-4$.

8 Reiestad F, Kvalheim L, Mcllvaine WB. Interpleural catheter in the management of acute thoracic herpes zoster. Regional Anesthesia (In press).

9 Sihota MK, Ikuta PT, Holmblad BR, Reiestad F, Zsigmond $E K$. Successful pain management of chronic pancreatitis and post herpetic neuralgia with intrapleural technique. Regional Anesthesia 1988; 13:2S:40.

10 Duranni $Z$, Winnie AP, Ikuta $P$. Interpleural catheter analgesia for pancreatic pain. Anesth Analg 1988; 67: 479-81.

11 Cousins MB, Bridenbaugh PO. Neural Blockade 2nd Ed. Philadelphia; Lippincott 1988, 520.

12 Kuntz A. The autonomic nervous system. Philadelphia; Lea \& Feibiger 1953, 255.

\section{Résumé}

L'analgésie intrapleurale peut soulager efficacement plusieurs types de douleurs chroniques. Pendant cinq à dix jours, nous avons injecté quotidiennement $30 \mathrm{ml}$ de bupivacaïne 0.5 pour cent avec adrénaline $\left(5 \mu \mathrm{g} \cdot \mathrm{ml}^{-1}\right)$ dans un cathéter pleural percutané à 11 patients souffrant de pancréatite chronique depuis 24 à 38 mois. Ils sont alors demeurés asymptomatiques pendant une période de 24 à 40 semaines. C'est un type d'analgésie sûr, simple et efficace qu'on peut l'utiliser en externe. 